\title{
Emergence of Glutaraldehyde-Resistant Pseudomonas aeruginosa
}

\author{
Sarah Tschudin-Sutter, MD; Reno Frei, MD; ${ }^{2}$ Günter Kampf, MD; ${ }^{3,4}$ Michael Tamm, MD; ${ }^{5}$ Eric Pflimlin, RN; ${ }^{6}$ \\ Manuel Battegay, MD; ${ }^{1}$ Andreas Franz Widmer, MD, MSc ${ }^{1}$
}

\begin{abstract}
oвjective. In November 2009, routine sampling of endoscopes performed to monitor the effectiveness of the endoscope-cleaning procedure at our hospital detected Pseudomonas aeruginosa. Herein we report the results of the subsequent investigation.

DESIGN AND METHODS. The investigation included environmental cultures for source investigation, molecular analysis by pulsed-field gel electrophoresis (PFGE) to reveal the identity of the strains, and determination of the bactericidal activity of the glutaraldehyde-based disinfectant used for automated endoscope reprocessing. In addition, patient outcome was analyzed by medical chart review, and incidence rates of clinical samples with $P$. aeruginosa were compared.
\end{abstract}

Setting. The University Hospital of Basel is an 855-bed tertiary care center in Basel, Switzerland. Approximately 1,700 flexible bronchoscopic, 2,500 gastroscopic, 1,400 colonoscopic, 140 endoscopic retrograde cholangiopancreatographic, and 140 endosonographic procedures are performed annually.

Results. P. aeruginosa was detected in samples obtained from endoscopes in November 2009 for the first time since the initiation of surveillance in 2006. It was found in the rinsing water and in the drain of 1 of the 2 automated endoscope reprocessors. PFGE revealed 2 distinct $P$. aeruginosa strains, one in each reprocessor. The glutaraldehyde-based disinfectant showed no activity against the 2 pseudooutbreak strains when used in the recommended concentration under standard conditions. After medical chart review, 6 patients with lower respiratory tract and bloodstream infections were identified as having a possible epidemiological link to the pseudo-outbreak strain. conclusions. This is the first description of a pseudo-outbreak caused by $P$. aeruginosa with reduced susceptibility to an aldehydebased disinfectant routinely used in the automated processing of endoscopes.

Infect Control Hosp Epidemiol 2011;32(12):1173-1178

Since its introduction in the 1960 s, flexible endoscopy has become standard of care for many indications in which open surgery is mandatory. Approximately 500,000 bronchoscopic examinations and 10 million gastrointestinal endoscopic examinations are performed in the United States annually. ${ }^{1}$ Despite the large number of endoscopic examinations performed, hospital-acquired infections attributable to flexible endoscopy are rare. The American Society of Gastrointestinal Endoscopy estimated the risk as approximately 1 in 1.8 million gastrointestinal procedures. ${ }^{2}$ The actual transmission of infectious organisms during endoscopic examination, however, may go unrecognized because of inadequate surveillance and the lack of formal, prospective surveillance data, which can lead to unrecognized or unreported outbreaks. ${ }^{3}$ Although such outbreaks are relatively uncommon, endoscopes are the most frequent cause of outbreaks of device-related hospitalacquired infection. ${ }^{4}$ Most of the outbreaks related to endoscopes involved waterborne organisms, such as gram-negative rods and Mycobacterium species. Pseudomonas aeruginosa is the organism that is most commonly detected in gastrointestinal endoscopy-associated and bronchoscopy-associated outbreaks. $^{5}$

Failure to follow recommended cleaning and disinfection procedures probably constitutes the single most important factor leading to endoscopic transmission of microorganisms and is the most common cause of outbreaks. ${ }^{6}$ There have been a few notable exceptions in which problems related to the endoscopes themselves have lead to contamination despite the use of an adequate reprocessing technique. ${ }^{7,8}$

In November 2009, the results of routine sampling of endoscopes showed growth of $P$. aeruginosa. Such microbiological surveillance is performed twice yearly and was initiated 1999 to monitor the performance of the endoscope reprocessor. Herein we report the results of the subsequent pseudo-outbreak investigation.

Affiliations: 1. Division of Infectious Diseases and Hospital Epidemiology, University Hospital Basel, Basel, Switzerland; 2. Division of Clinical Microbiology, University Hospital Basel, Basel, Switzerland; 3. Bode Chemie, Scientific Affairs, Hamburg, Germany; 4. Institute for Hygiene and Environmental Medicine, Ernst-Moritz-Arndt University, Greifswald, Germany; 5. Division of Pulmonary Medicine, University Hospital Basel, Basel, Switzerland; 6. Division of Medical Diagnostics, University Hospital Basel, Basel, Switzerland.

Received May 27, 2011; accepted July 30, 2011; electronically published October 27, 2011.

(C) 2011 by The Society for Healthcare Epidemiology of America. All rights reserved. 0899-823X/2011/3212-0004\$15.00. DOI: 10.1086/662624 


\section{METHODS}

\section{Setting}

The University Hospital of Basel is an 855-bed tertiary care center in Basel, Switzerland. Approximately 1,700 flexible bronchoscopic, 2,500 gastroscopic, 1,400 colonoscopic, 140 endoscopic retrograde cholangiopancreatographic, and 140 endosonographic procedures are performed annually. A large majority of bronchoscopic examinations include bronchoalveolar lavage, in which sterile saline is instilled into the lower airways and then aspirated to obtain specimens. Biopsies are performed in most of the other endoscopic procedures.

\section{Endoscope Cleaning Procedures}

Endoscopes used for gastrointestinal and bronchoscopic procedures are cleaned by trained personnel in accordance with national guidelines ${ }^{9}$ and the manufacturer's recommendations (Olympus and Pentax). After use, the instrument's outer surface is wiped to avoid surface drying. Endoscopes are then immediately soaked in cleaner and disinfectant solution (Sekusept aktiv) based on peracetic acid. Thereafter, they are cleaned manually by wiping the outer surface and brushing the inner channels. Endoscopes then undergo high-level disinfection in an automated endoscope washer disinfector (Hamo Endoclean 2000; Steris) in which glutaraldehyde and glyoxal $(3.5 \mathrm{~g}$ and $6.0 \mathrm{~g}$ per $100 \mathrm{~g}$, respectively; neodisher Septo V459) are used as liquid disinfectant. According to the manufacturer's recommendation, the disinfectant was used at a working concentration of $1 \%$ at a temperature of $50^{\circ} \mathrm{C}-60^{\circ} \mathrm{C}$ for $5-10 \mathrm{~min}$. Finally, the channels are dried with pressurized air. Logbooks are used to record when water filters and solutions are changed in the reprocessors.

\section{Surveillance}

As part of the quality assurance program to monitor the effectiveness of the endoscope cleaning procedure, endoscopes were routinely sampled twice yearly.

\section{Reinforced Cleaning Procedures}

From January through February 2010, after detection of the pseudo-outbreak of $P$. aeruginosa infection, the disinfectant used for high-level disinfection in the automated endoscope reprocessor was changed to Neodisher Septo DN 2 (20 g of glutaraldehyde per $100 \mathrm{~g}$ of disinfectant). According to the manufacturer's recommendation, the disinfectant was used at a working concentration of $1 \%$ at a temperature of $50-55^{\circ} \mathrm{C}$ for $5 \mathrm{~min}$. In addition, a rinse aid (Neodisher mediklar) was added to the automated cleaning procedure, and thermal disinfection of the automated endoscope reprocessor was performed 3 times weekly by running the processor while empty at $90^{\circ} \mathrm{C}$ for $10 \mathrm{~min}$.

From March 2010, the concentration of the disinfectant Neodisher Septo DN 2 was increased to $2 \%$ and the application time was increased to $10 \mathrm{~min}$. In addition, the automated endoscope reprocessors were run while empty once a week with the detergent Neodisher SeptoClean (consisting of $<5 \%$ nonionic surfactants, amphoteric surfactants, and $15 \%-30 \%$ phosphates), and thermal disinfection was reduced to once weekly.

\section{Reinforced Surveillance}

After introduction of the reinforced cleaning procedures, surveillance was intensified by sampling the rinsing water from the automated reprocessors twice weekly and sampling endoscopes twice monthly.

\section{Microbiological Methods}

Routine sampling of endoscopes was performed by injecting $20 \mathrm{~mL}$ of sterile saline solution $(\mathrm{NaCl} 0.9 \%)$ into each air/ water and suction/biopsy channel according to recommendations outlined by the Robert Koch Institute. ${ }^{10}$ The volumes of solution injected were recovered at the distal end of the endoscope. The number of viable bacteria in the samples collected was determined by conventional culture after inoculation on blood agar and filtration on $0.45 \mu \mathrm{m}$ membrane filters. After 72 hours of incubation at $35^{\circ} \mathrm{C}$, the number of colony-forming units (CFUs) was counted, and the results were expressed as the number of viable microorganisms. Subcultures were performed for identification.

During the pseudo-outbreak investigation, swab samples from the interior of the automated endoscope reprocessor (Hamo Endoclean 2000; Steris), along with samples of cleaning solutions and of solutions and water used in the automated endoscope reprocessors, were sent for bacterial culture. Furthermore, swab samples were taken from all supplying water pipes. The water filters of the automated endoscope reprocessors were exchanged and were also cultured.

Surface samples were obtained with the use of sterile moistened cotton swabs. Bacterial cultures of the used rinsing water, obtained directly from the automated endoscope reprocessors, were performed once to twice weekly. Furthermore, routine sampling of endoscopes was performed at least weekly.

The bactericidal activity was determined using the standard method for testing the bactericidal activity of chemical disinfectants according to the German Society for Hygiene and Microbiology. ${ }^{11}$ The disinfectant Neodisher Septo DN 2 (glutardialdehyde $20 \mathrm{~g}$ per $100 \mathrm{~g}$ ) was tested for activity against the pseudo-outbreak isolate of $P$. aeruginosa and against the reference strain $P$. aeruginosa ATCC 15442. From 1.5 to $5 \times 10^{9} \mathrm{CFU}$ of the isolates were diluted to $10^{-5} \mathrm{CFU} / \mathrm{mL}$, then $8 \mathrm{~mL}$ of the disinfectant were added and a quantitative suspension test with and without an organic load $(0.2 \%$ albumin) was performed. After exposure times of 5 and 10 $\min$, respectively, at $50^{\circ} \mathrm{C}$, the disinfectant was inactivated and the suspension was cultured for 48 hours at $36^{\circ} \mathrm{C}$. If a reduction factor of 5 in the number of CFU was achieved, the disinfectant was regarded as effective according to EN 1040 (available at http://www.cen.eu).

Molecular typing to determine the clonality and the trans- 
mission pattern of $P$. aeruginosa was performed by pulsedfield gel electrophoresis (PFGE) as described elsewhere. ${ }^{12}$

\section{Interpretation of Endoscope Sampling Results}

Results were interpreted according to the guidelines of the Robert Koch Institute. ${ }^{10}$ The threshold value for the concentration of CFU was less than or equal to $1 \mathrm{CFU} / \mathrm{mL}$ of recovery solution, and detection of any of the following bacteria was regarded as an indicator for insufficient disinfection, independent of the number of CFU: Enterobacteriaceae, Enterococci, Pseudomonas aeruginosa, other nonfermenting gram-negative bacteria, Staphylococcus aureus, and viridans streptococci.

\section{Patient Outcomes}

All patients who underwent endoscopic examination from April through November 2009 were identified from the endoscopy database and were retrospectively assessed for the presence of colonization or infection due to $P$. aeruginosa. If $P$. aeruginosa was detected in any sample after endoscopic examination, an epidemiological link was assessed by full chart review of 2 board-certified infectious diseases specialists. Transmission was regarded as possible if the strain detected in the clinical specimen revealed the same phenotypic features (ie, the same susceptibility test result) as the strain detected in the endoscopes and if prior colonization or infection of the patient with $P$. aeruginosa was not documented in either the medical records or in the computerized database of the microbiology laboratory or if prior colonization or infection with $P$. aeruginosa was present (as identified by medical chart review or documented in the database of the microbiology laboratory) but susceptibilty test results differed for at least 2 of the following antibiotic classes: quinolones, aminoglycosides, carbapenems, cefepime, and piperacillin-tazbactam. Upper and lower respiratory tract and bloodstream infections were defined according to the criteria of the Centers for Disease Control and Prevention. ${ }^{13}$ From December 2009 through January 2010, all consecutive samples (specimens recovered from the respiratory tract or from tissue and blood cultures) with detection of $P$. aeruginosa from patients who had undergone endoscopic examination within the previous 6 months were prospectively collected and molecularly typed.

Furthermore, incidence rates of the number of clinical samples with detection of $P$. aeruginosa were compared for the years 2009 and 2008. The number of patients who underwent endoscopic examination within 30 days before detection of $P$. aeruginosa in a respiratory tract or tissue sample or in blood cultures was compared for the years 2009 and 2008.

\section{RESULTS}

Routine surveillance to monitor the effectiveness of the endoscope cleaning procedure detected $P$. aeruginosa in 23 (32\%) of 73 samples from a total of 40 endoscopes in November 2009. This pathogen had not been detected since the initiation of routine surveillance in 1999. In the following samples, obtained from endoscopes during the period from November 4 through December 7, 2009, P. aeruginosa was detected in 29 (29\%) of 99 investigational samples.

\section{Endoscope Cleaning Procedures}

Endoscopic and reprocessing procedures were observed onsite by an infection control practitioner and hospital epidemiologist. No significant breaches in technique were noted, but several changes were noted during the last year before the pseudo-outbreak. Examination of the maintenance records for the automated endoscope reprocessors demonstrated that the drying program had been reduced from 10 $\mathrm{min}$ to $5 \mathrm{~min}$ to expedite turnaround time. In addition, the rinse aid was discontinued in July 2009 to diminish foaming. The microprocessor running the process was double-checked by a representative of the manufacturer, and the written protocol did not reveal any deviation from the normal procedure. However, a manual check identified failure of the reprocessor to reach the required target temperature, although only in very few of the monitored cycles.

\section{Sampling because of Pseudo-Outbreak Investigation}

A total of 103 environmental samples were taken from November through December 2009. P. aeruginosa could be detected in the rinsing water as well as in the drain of 1 of the 2 automated endoscope reprocessors (Table 1). However, the pathogen could not be detected in the supplying water pipes, filters, or ventilation shafts of the reprocessors, nor could it be detected in the hospital water supply tanks or in any of the cleaning solutions or disinfectants used for reprocessing the endoscopes.

\section{Molecular Typing}

PFGE revealed 2 distinct $P$. aeruginosa strains (A and $\mathrm{B}$ ) recovered from the rinsing water of the 2 different automated endoscope reprocessors as well as from the drain of 1 of the reprocessors. One automated reprocessor was contaminated with strain $A$, whereas the other was contaminated with strain B.

During the pseudo-outbreak, all strains from patients with $P$. aeruginosa infection who had undergone endoscopic examination within the previous 6 months were stored at $-70^{\circ} \mathrm{C}$. These strains were detected from clinical samples submitted to the laboratory or were obtained by the infectious disease consultation service. Molecular typing of all consecutive patient samples $(n=18)$ in which $P$. aeruginosa was detected did not reveal a clone that matched one of the strains isolated from the automated reprocessors.

\section{Bactericidal Tests}

The disinfectant Neodisher Septo DN 2 (glutardialdehyde 20 $\mathrm{g}$ per $100 \mathrm{~g}$ ) was tested for activity against the pseudooutbreak isolate of $P$. aeruginosa and against the reference strain $P$. aeruginosa ATCC 15442 . For the reference strain, a 
TABLE 1. Results of Cultures of Specimens from Environmental Sources

\begin{tabular}{ll}
\hline Source and type of specimen & Pseudomonas aeruginosa isolated on culture \\
\hline Washers (automated endoscope reprocessors) & \\
Interior of washer (surface samples) & No \\
Supplying waterpipes (surface samples) & No \\
Filters & No \\
Rinsing water & Yes \\
Ventilation shaft & No \\
Drains & Yes \\
Water-supplying tanks of the hospital & \\
Water & No \\
Disinfectant & No \\
Cleaning solutions & No \\
\hline
\end{tabular}

reduction factor greater than $5 \log _{10} \mathrm{CFU}$ was achieved when using concentrations of $0.5 \%$ to $2 \%$ for $5 \mathrm{~min}$ and $10 \mathrm{~min}$ at $20^{\circ} \mathrm{C}$ and $55^{\circ} \mathrm{C}$. For the 2 pseudo-outbreak strains, a reduction factor greater than 5 could only be achieved when using $2 \%$ of the disinfectant for $10 \mathrm{~min}$ at $55^{\circ} \mathrm{C}$ (Table 2). At $20^{\circ} \mathrm{C}$, bacterial growth could still be detected with a reduction factor of less than 5 , which confirmed dramatically reduced bactericidal activity (Table 3 ).

\section{Reinforced Cleaning Procedures}

After introduction of the reinforced cleaning procedures, $P$. aeruginosa could no longer be detected in the samples obtained from endoscopes. However, in the cultures of the rinsing water, which was checked twice weekly, $P$. aeruginosa reemerged at the beginning of March 2010. PFGE revealed identity to 1 of the 2 pseudo-outbreak strains (strain A). Cleaning procedures were changed as described above, on the basis of the bactericidal test results. After March 2010, $P$. aeruginosa was no longer detected in either the samples obtained from the endoscopes or the rinsing water of the automated reprocessors.

\section{Patient Outcomes}

A total of 63 patients who underwent endoscopic examination from April through November 2009 had samples (obtained either from the respiratory tract or from tissue and blood cultures after endoscopy was performed) that revealed P. aeruginosa. The epidemiologic investigations failed to identify a link in 20 of 63 patients. After medical chart review by 2 infectious disease specialists, lower respiratory tract and bloodstream infections possibly caused by the pseudooutbreak strain were detected in 6 patients.

The comparison of the number of patients who underwent endoscopic examination 30 days before detection of P. aeruginosa in a respiratory tract or tissue sample or in blood cultures showed no increase, with 30 patients fitting this definition in 2008 and 27 patients fitting this definition in 2009. The number of procedures performed was 5,544 in 2008 and 5,630 in 2009 , which accounted for $0.54 \%$ (30 of 5,544 ) and $0.48 \%(27$ of 5,630$)$ of the patients with detection of P. aeru- ginosa in a clinical specimen within 30 days after endoscopic examination.

\section{DISCUSSION}

This is, to our knowledge, the first report of a pseudooutbreak caused by contamination of automated endoscope reprocessors with 2 different strains of $P$. aeruginosa resistant to aldehydes and heat. No increase in the incidence of infection caused by this pathogen could be detected during the outbreak period. However, 6 patients could have potentially been infected by contaminated endoscopes.

Glutaraldehyde has been used as a high-level disinfectant for approximately 30 years and displays potent bactericidal, fungicidal, mycobactericidal, sporicidal, and virucidal activity, which is based on its interaction with amino groups in proteins and enzymes. ${ }^{14}$ Glutaraldehyde-resistant mycobacteria have been revealed as a source of recontamination of endoscopes and have been detected in endoscope washers, which has led to misdiagnosis of infections. ${ }^{15,16}$ Furthermore, these pathogens were found to be cross-resistant to peracetic acid. ${ }^{16}$ Nevertheless, an increase in the activity of glutaraldehyde could be obtained by increasing the temperature of the washer to $50^{\circ} \mathrm{C} .{ }^{16} \mathrm{~A}$ strain of $P$. aeruginosa resistant to disinfection with glutaraldehyde was isolated from endoscopes and from tap water by Kovacs et $\mathrm{al}^{17}$ in 1998 . However, glutaraldehyde was used at room temperature, and resistance testing was performed at $37^{\circ} \mathrm{C}$. In contrast, tests revealed our pseudo-outbreak strains to be resistant even when using the recommended glutaraldehyde concentration of $1 \%$ at $55^{\circ} \mathrm{C}$, and they survived thrice-weekly thermal disinfection at $90^{\circ} \mathrm{C}$.

Resistance to high-level disinfection with glutaraldehyde of $P$. aeruginosa has been reported in dental and medical devices $^{18}$ but was associated with the pathogen being entrapped in lubricants used in dental handpieces and endoscopes and with the disinfectant not being able to penetrate the lubricant.

$P$. aeruginosa is a pathogen that is well known for its ability to adapt to changing environmental conditions. In chronic infection, this pathogen can survive attacks by the host immune system and the action of antimicrobial substances by undergoing phenotypic and genetic adaptation, resulting in 
TABLE 2. Bactericidal Tests with Glutaraldehyde $(20 \mathrm{~g} / 100 \mathrm{~g})$ Applied for $10 \mathrm{Min}$ at $55^{\circ} \mathrm{C}$

\begin{tabular}{lcc}
\hline Strain, glutaraldehyde concentration, \% & Bacterial growth & Reduction factor of no. of CFU \\
\hline Pseudomonas aeruginosa (strain A) & & \\
0.5 & Yes & $<4.12$ \\
1.0 & Yes & $>5.50$ \\
2.0 & No & $>5.50$ \\
P. aeruginosa (strain B) & & \\
0.5 & Yes & $<4.00$ \\
1.0 & Yes & 4.42 \\
2.0 & No & $>5.39$ \\
P. aeruginosa (ATCC 15442) & & \\
0.5 & No & $>5.55$ \\
1.0 & No & $>5.55$ \\
2.0 & No & $>5.55$ \\
\hline
\end{tabular}

the progressive loss of virulence and the development of increased persistence. However, the underlying strategies and mechanisms employed by $P$. aeruginosa are still relatively poorly understood. ${ }^{19}$

The question arises whether resistance to disinfectants is attributable to primary resistance or to the development of resistance, similar to the development of resistance to antibiotics. In 1976, 5 fully susceptible laboratory strains were described that were exposed for longer periods of time to sublethal doses of 4 basic constituents of disinfectants (phenole, isopropanole, formaldehyde, and chloramine 80). After multiple passages, an increase in resistance against formaldehyde and chloramine 80 could be noted. ${ }^{20}$ The organisms tested were Staphylococcus aureus, Escherichia coli, Aerobacter cloacae, $P$. aeruginosa, and Klebsiella pneumoniae. Spicher et $\mathrm{al}^{21}$ reported that strains of $P$. aeruginosa vary widely in their susceptibility to formaldehyde, with the need to use concentrations almost 3 times as high for the most resistant strain than for the most susceptible strain to obtain equal microbicidal effects.

Possible mechanisms of action could be enzymatic degradation and extracellular and intracellular penetration barriers. Formaldehyde degredation could be detected photometrically in $P$. aeruginosa strains. The highest formalde- hyde resistance correlated with a formaldehyde dehydrogenase activity that was 100 times higher than that for a relatively susceptible ATCC strain. ${ }^{22}$ Interestingly, the tested strains exhibited markedly differing resistance to formaldehyde, with some environmental isolates growing even at concentrations in the range of commonly used disinfectant solutions.

Our strains may have become resistant because of the use of glutaraldehyde at suboptimal application durations and possibly because of inadequate temperatures, because our automated reprocessors may not have consistently achieved a temperature of $55^{\circ} \mathrm{C}$ as a result of inconsistent failure of the microprocessors caused by wear. In addition, the rinse aid, which was discontinued, facilitates and accelerates the drying process, and the drying program had been reduced from 10 min to $5 \mathrm{~min}$; these changes may have contributed to the contamination of the endoscopes, especially because gramnegative bacteria do not survive as long as grampositive bacteria on dry surfaces. ${ }^{23}$

The susceptibility of $P$. aeruginosa to different chemical germicides was also tested by Sagripanti et al, ${ }^{24}$ which revealed that this pathogen, together with $S$. aureus, showed the most resistance. ${ }^{24}$ Less than 4 logs inactivation were observed after treatment with glutaraldehyde or hypochlorite of an ATCC

\begin{tabular}{|c|c|c|}
\hline Strain, glutaraldehyde concentration, $\%$ & Bacterial growth & Reduction factor of no. of CFU \\
\hline \multicolumn{3}{|l|}{ Pseudomonas aeruginosa (strain A) } \\
\hline 0.5 & Yes & $<4.11$ \\
\hline 1.0 & Yes & $<4.11$ \\
\hline 2.0 & Yes & $<4.67$ \\
\hline \multicolumn{3}{|l|}{ P. aeruginosa (strain B) } \\
\hline 0.5 & Yes & $<4.16$ \\
\hline 1.0 & Yes & $<4.16$ \\
\hline 2.0 & Yes & $<4.16$ \\
\hline \multicolumn{3}{|l|}{ P. aeruginosa (ATCC 15442) } \\
\hline 0.5 & No & $>5.54$ \\
\hline 1.0 & No & $>5.54$ \\
\hline 2.0 & No & $>5.54$ \\
\hline
\end{tabular}


strain (ATCC 27853) of $P$. aeruginosa. Sagripanti et al ${ }^{24}$ suggested that resistance to disinfectants may be more important than pathogenicity in determining the relative prominence of a organism as an agent responsible for hospital-acquired infection. Species that more frequently survived exposure to germicidal agents were also the most commonly reported in association with hospital-acquired infection. ${ }^{24}$

Although glutaraldehyde is the most commonly used chemical for reprocessing endoscopic equipment, our results suggest that it may not be the most effective product. $P$. aeruginosa, which is one of the most important hospitalacquired pathogens, can become resistant, especially when there is not compliance with the recommended temperature and application time of disinfection. This new data may expedite the current trend to replace aldehydes with peracetic acid. Resistance to disinfectants and resistance to heat have emerged and can cause pseudo-outbreaks in healthcare settings.

\section{ACKNOWLEDGMENTS}

Financial support. The University Hospital of Basel funded in part the microbiological analyses of the samples as part of the quality improvement program.

Potential conflicts of interest. G.K. is employed by Bode Chemie. All other authors report no conflicts of interest relevant to this article.

Address correspondence to Andreas F. Widmer, MD, MSc, Division of Infectious Diseases and Hospital Epidemiology, University Hospital Basel, Petersgraben 4, CH-4031 Basel, Switzerland (widmerA@uhbs.ch).

Presented in part: 48th Annual Meeting of the Infectious Diseases Society of America; Vancouver, Canada; October 2010.

\section{REFERENCES}

1. Centers for Disease Control and Prevention. Vital and health statistics: ambulatory and inpatient procedures in the United States, 1996. http:/www.cdc.gov/nchs/data. Accessed March 15, 2003.

2. Kimmey MB, Burnett DA, Carr-Locke DL, et al. Transmission of infection by gastrointestinal endoscopy. ASGE Technology Assessment Committee position paper. Gastrointest Endosc 1993; 39:885-888.

3. Centers for Disease Control and Prevention. Bronchoscopy related infections and pseudoinfections: New York, 1996 and 1998. MMWR Morb Mortal Wkly Rep 1999;48:557-560.

4. Spach DA, Silverstein FE, Stamm WE. Transmission of infection by gastrointestinal endoscopy and bronchoscopy. Ann Intern Med 1993;118:117-128.

5. Srinivasan A. Epidemiology and prevention of infections related to endoscopy. Curr Infect Dis Rep 2003;5:467-472.

6. Culver DA, Gordon SM, Mehta AC. Infection control in the bronchoscopy suite: a review of outbreaks and guidelines for prevention. Am J Respir Crit Care Med 2003;167:1050-1056.

7. Srinivasan A, Wolfenden LL, Song $X$, et al. An outbreak of
Pseudomonas aeruginosa infections associated with flexible bronchoscopes. N Engl J Med 2003;348:221-227.

8. Kirschke DL, Jones TF, Craig AS, et al. Pseudomonas aeruginosa and Serratia marcescens contamination associated with a manufacturing defect in bronchoscopes. $N$ Engl J Med 2003;348: 214-220.

9. Schweizerische Gesellschaft für Gastroenterologie. Empfehlungen zur Desinfektion von flexilblen Endoskopen, 2009. http:// www.sggssg.ch/Dokumente/Merkblaetter/Hygiene_Empfehlungeni _2009_D.pdf. Accessed September 29, 2011.

10. Anforderungen an die Hygiene bei der Aufbereitung flexibler Endoskope und endoskopischen Zusatzinstrumentariums Empfehlung der Kommission für Krankenhaushygiene und Infektionsprävention beim Robert Koch-Institut (RKI). Bundesgesundheitsbl-Gesundheitsforsch-Gesundheitsschutz 2002; 45:395-411. Berlin: Springer, 2002.

11. Deutsche Gesellschaft für Hygiene und Mikrobiologie. Prüfung und Bewertung chemischer Desinfektionsverfahren: Stand 12.07.1991. Hyg Med 1991;special issue:1-8.

12. Stranden A, Frei R, Widmer AF. Molecular typing of methicillinresistant Staphylococcus aureus: can PCR replace pulsed-field gel electrophoresis? J Clin Microbiol 2003;41:3181-3186.

13. NNIS manual: National Nosocomial Infection Surveillance System. Atlanta: Centers for Disease Control and Prevention, 1994.

14. Russell AD. Glutaraldehyde: current status and uses. Infect Cont Epidemiol 1994;15:724-733.

15. Griffiths PA, Babb JR, Bradley CR, Fraise AP. Glutaraldehyderesistant Mycobacterium chelonae for endoscope washer disinfectors. J Appl Microbiol 1998;82:519-526.

16. Van Klingeren B, Pullen W. Glutaraldehyde resistant mycobacteria from endoscope washers. J Hosp Infect 1993;25:147-149.

17. Kovacs BJ, Aprecio RM, Kettering ID, Chen YK. Efficacy of various disinfectants in killing a resistant strain of Pseudomonas aeruginosa by comparing zones of inhibition: implications for endoscopic equipment reprocessing. Am J Gastroenterol 1998; 93:2057-2059.

18. Lewis DL, Arens M. Resistance of microorganisms to disinfection in dental and medical devices. Nat Med 1995;1:956-958.

19. Malone JG, Jaeger T, Spangler C, et al. YfiBNR mediates cyclic di-GMP dependent small colony variant formation and persistence in Pseudomonas aeruginosa. PLoS Pathog 2010;6:e1000804.

20. Wille B. Possibility of the development of resistance to disinfectants in microorganisms [in German]. Zentralbl Bakteriol Orig B 1976;162:217-220.

21. Spicher G, Peters J. Microbial resistance to formaldehyde. I. Comparative quantitative studies in some selected species of vegetative bacteria, bacterial spores, fungi, bacteriophages and viruses. Zentralbl Bakteriol Orig B 1976;163:486-508.

22. Hingst V, Maiwald M, Sonntag HG. Investigations on the enzymatic degradation of formaldehyde by isolates of the species Pseudomonas aeruginosa. Zentralbl Bakteriol Hyg B 1987;184: 167-181.

23. Kramer A, Schwebke I, Kampf G. How long do nosocomial pathogens persist on inanimate surfaces? a systematic review. BMC Infect Dis 2006;6:130.

24. Sagripanti JL, Eklund CA, Trost PA, et al. Comparative sensitivity of 13 species of pathogenic bacteria to seven chemical germicides. Am J Infect Control 1997;25:335-339. 